\title{
Wind-Blown Mosquitoes and Introduction of Japanese Encephalitis into Australia
}

\author{
Scott A. Ritchie* and Wayne Rochestert \\ *Tropical Public Health Unit, Queensland Health, Cairns, Queensland, Australia; and \\ †University of Queensland, St. Lucia, Queensland, Australia
}

\begin{abstract}
Backtrack simulation analysis indicates that wind-blown mosquitoes could have traveled from New Guinea to Australia, potentially introducing Japanese encephalitis virus. Large incursions of the virus in 1995 and 1998 were linked with low-pressure systems that sustained strong northerly winds from New Guinea to the Cape York Peninsula.
\end{abstract}

J apanese encephalitis (J E) is a recently emerged disease in Australia (1). Two major incursions have occurred, in 1995 and 1998; the earlier outbreak caused three human cases on Badu Island in Torres Strait (2,3). In 1996-97, J E virus activity was limited to Saibai Island, the northernmost island in Torres Strait (3). The 1998 incursion was more widespread, with J E activity from the Torres Strait south to the Mitchell River on Cape York Peninsula (3). Human serosurveys in the Western Province of Papua New Guinea, which-along with I rian J aya-is considered a probable source of the virus in the Australian incursions (4), indicate that J E virus was not confirmed in the region before 1989 (1). Thus, the incursions of J E virus into Australia are novel. The Culex annulirostris mosquito is likely the primary vector (5).

J E virus may have been introduced into Australia by infected birds (2), frugivorous bats $(J$. Mackenzie, pers. comm.), or mosquitoes $(2,3)$. However, the widespread, sudden appearance of JE virus in the Torres Strait and Cape York Peninsula suggests that it was an episodic incursion potentially mediated by mosquitoes $(2,3)$. Cx. tritaeniorhynchus, an Asian J E virus vector, is migratory in China (6) and has been collected at altitudes $>100 \mathrm{~m}$ in India and China $(6,7)$. In New South Wales, Australia, Cx. annulirostris has been collected at heights up to $310 \mathrm{~m}$ with an estimated flight range of 594 to $648 \mathrm{~km}$, well beyond the $160 \mathrm{~km}$ from New Guinea to northernmost Cape York Peninsula (8). Similar incursions of bluetongue virus into northern Australia (9) are thought to be mediated by wind-blown, exotic Culicoides midges from Indonesia (10).

\section{The Study}

We used computer simulation to investigate whether winds were sufficient to have carried mosquitoes from New Guinea to the Torres Strait and Cape York Peninsula, potentially introducing JE virus into northern Australia. The Helicoverpa migration model incorporates wind speed and direction to simulate migratory flights for Helicoverpa spp. noctuid moths in Australia (11). We used wind speed and direction generated by the Regional Assimilation and Prognosis System (1995-96) and the Limited Area Prediction System (1996-97 onwards) of the Australian Bureau of

Address for correspondence: Scott Ritchie, Tropical Public Health Unit, Queensland Health, PO Box 1103 Cairns, Queensland 4870 Australia; fax: 61-740-311-440; e-mail: Scott_Ritchie@health.qld.gov.au
Meteorology Research Centre (Melbourne). Backtrack simulations were used to map flight paths of mosquitoes from a focus of J E virus activity back to their potential source. Simulation parameters used were a) flight time: 20:00 Australian Eastern Standard Time; b) flight duration: 0-11 hours; c) flight altitude: $100-400 \mathrm{~m}$; and d) flight speed: 0 meters/ second. Flight duration and height were randomly sampled from uniform probability distributions in Monte Carlo simulations of 1,000 replicates (mosquitoes) each. The estimated flight paths are conservative; trajectories would have been longer if we had included the mosquito downwind flight speed (an estimated 5 to $7 \mathrm{~km} / \mathrm{hr}$ [12]) and a longer flight time.

Backtrack simulations were run from December to March for the 1995-96 and 1997-98 seasons, encompassing the monsoon season, when westerly to northwesterly winds dominate. In 1994-95, simulations were limited to J anuary 16-20 and February 8 to March 31, 1995; flight trajectories on other days were estimated from maps of wind speed and direction provided by the Tropical Area Projection System (Bureau of Meteorology, Darwin, Australia). Simulations were run for Badu I sland in the Torres Strait, the northern peninsula area, and the mouth of the Mitchell River on Cape York Peninsula. These sites are $100 \mathrm{~km}, 160 \mathrm{~km}$, and $675 \mathrm{~km}$ from the New Guinea mainland, respectively (Figure 1). Badu Island had J E virus activity in March-April 1995 and February-March 1998, while activity was limited to February-May 1998 in the Cape York Peninsula sites.

The simulations indicate that winds sufficient to transport mosquitoes from New Guinea frequently reach Badu Island (mean 14.2\% [Table]). No association with J E activity has been confirmed. In 1994-95, the year of the initial incursion, only eight nights (6.6\%) had favorable winds. Conversely, in the 1995-96 and 1996-97 seasons, JE virus activity was limited to islands within $5 \mathrm{~km}$ of Papua New Guinea (3) despite favorable winds for transport to Badu Island on $17 \%$ of nights (Table). Both Cape York Peninsula locations had fewer nights with favorable winds (Table). Only on December 27, 1997, were winds sufficient to carry mosquitoes from New Guinea to the mouth of the Mitchell River (Figure 2).

Weather conditions before the 1995 and 1998 J E outbreaks suggest that low-pressure systems west of Cape York Peninsula could have carried mosquitoes from New Guinea to the study sites. On J anuary 19, 1995, a large monsoonal 


\section{Dispatches}

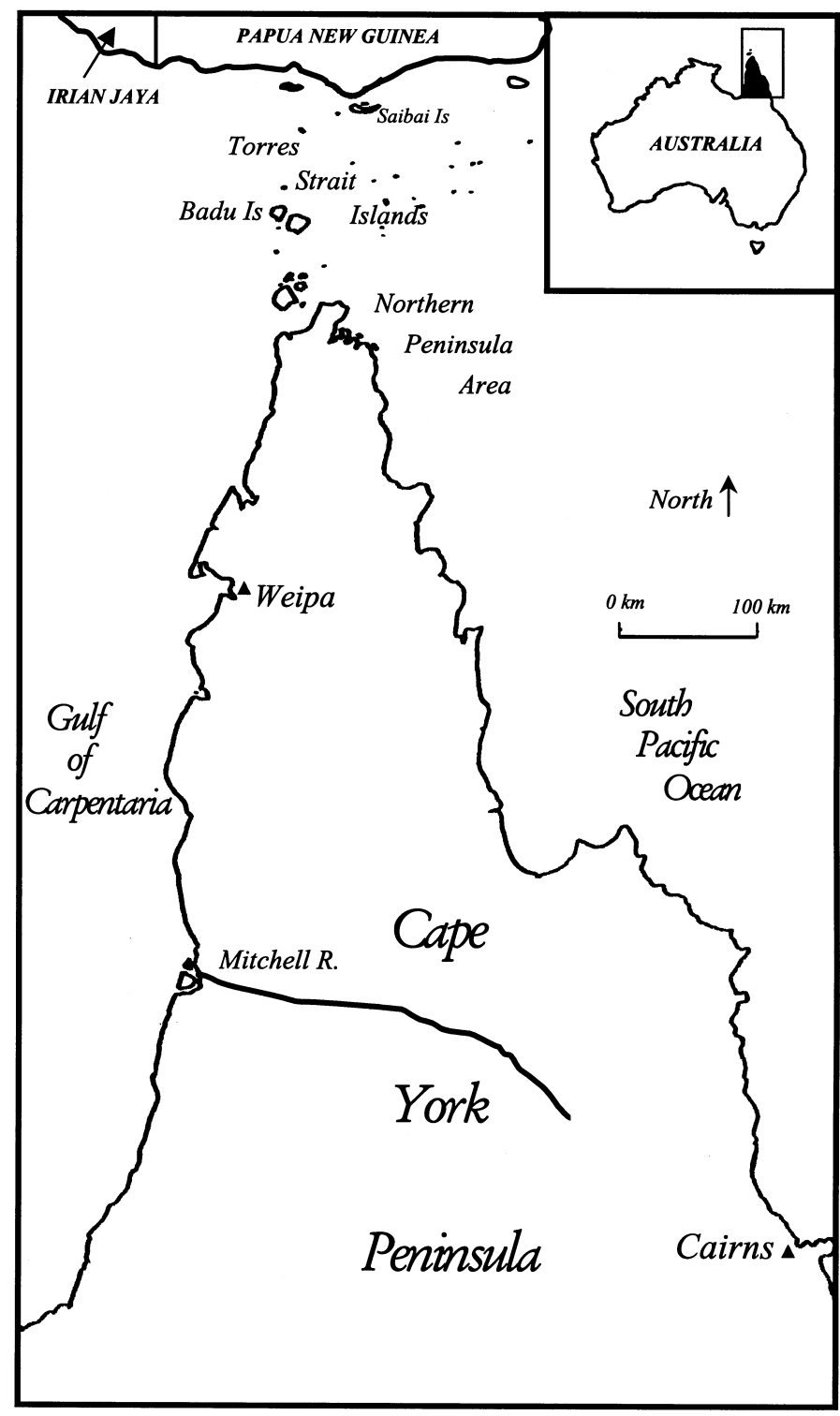

Figure 1. Map showing location of J apanese encephalitis foci (Badu I sland in the Torres Strait, the northern peninsula area, and the mouth of the Mitchell River in Cape York) used in backtrack simulations. low in the Northern Territory sustained 15 to $20 \mathrm{~km} / \mathrm{hour}$ northerly winds from southern Papua New Guinea across the Torres Strait into northernmost Cape York Peninsula. The weather preceding the widespread J E outbreak in 1998 was especially noteworthy. In December 1997, Tropical Cyclone Sid in the Gulf of Carpentaria west of Cape York Peninsula produced northerly winds of 36 to $72 \mathrm{~km} / \mathrm{hour}$, which were capable of carrying mosquitoes from $\mathrm{N}$ ew Guinea to the Northern peninsula area on December 27 (Figure 2). Furthermore, the system persisted in the area, sustaining northwesterly winds capable of carrying mosquitoes from New Guinea to Badu I sland and the northern peninsula area for 11 of 14 days and 8 of 14 days, respectively, from December 26, 1997, to J anuary 8, 1998.

The arrival dates of migrating mosquitoes in 1995 and 1997 would have allowed sufficient time for amplification of $\mathrm{J} E$ virus in vertebrate hosts and subsequent spillover into humans. In J apan, two cycles of J E viral amplification occur in pigs, with human cases peaking approximately 2 months after pigs are infected (13). Thus, for Badu Island, where human J E cases occurred in late March 1995 and in late February 1998 , J E virus was likely introduced in late J anuary 1995 and late December 1997, respectively. These dates correspond to the weather events described above.

\section{Conclusions}

Backtrack simulations indicate that winds sufficient to transport mosquitoes from New Guinea to Badu Island occurred frequently (Table). However, many favorable wind conditions were not followed by J E virus activity (e.g., 199596 [Table]), suggesting that other factors influence incursions of $\mathrm{E}$ virus.

Several conditions would have to be met to permit a large incursion of windblown, infected mosquitoes from $\mathrm{New}$ Guinea into Australia. First, there would have to be a sufficient amount of J E virus at the potential source of migrant mosquitoes. Results of human serologic tests indicate that $\mathrm{J} E$ virus has been active in southern Papua New Guinea since 1989 (4), especially in late 1997 and early 1998, when multiple human cases were reported (1). Second, large populations of J E virus-infected mosquitoes must be present. The southern part of New Guinea (approximately 160,000 km²)

Table. Number of days when winds could have carried mosquitoes from New Guinea to Badu Island in the Torres Strait and to the northern peninsula area and the mouth of the Mitchell River on Cape York Peninsula ${ }^{a}$

\begin{tabular}{lcccc}
\hline Year & No. of days & $\begin{array}{c}\text { Badu I sland } \\
\text { (Torres Strait) } \\
\text { days (\%) }\end{array}$ & $\begin{array}{c}\text { Northern peninsula area } \\
\text { (Cape York) } \\
\text { days (\%) }\end{array}$ & $\begin{array}{c}\text { Mouth of Mitchell River } \\
\text { (Cape York) } \\
\text { days (\%) }\end{array}$ \\
\hline $1994-95$ & 121 & $8(6.6)$ & $0(0)$ & $0(0)$ \\
$1995-96$ & 122 & $21(17.2)$ & $7(5.7)$ & $0(0)$ \\
$1996-97$ & 121 & $20(16.5)$ & $11(9.1)$ & $1(0.6)$ \\
$1997-98$ & 121 & $20(16.5)$ & $6.5(5.4)$ & $0.25(0.2)$ \\
\hline
\end{tabular}

${ }^{a}$ Based on backtrack simulations done during the monsoon season (December to March) for the seasons 1994-95 through $1997-98$.

${ }^{\mathrm{b}}$ Backtrack-simulated flight path with one or more pixels completely within the New Guinea mainland (e.g., Figure 1B). 


\section{Dispatches}
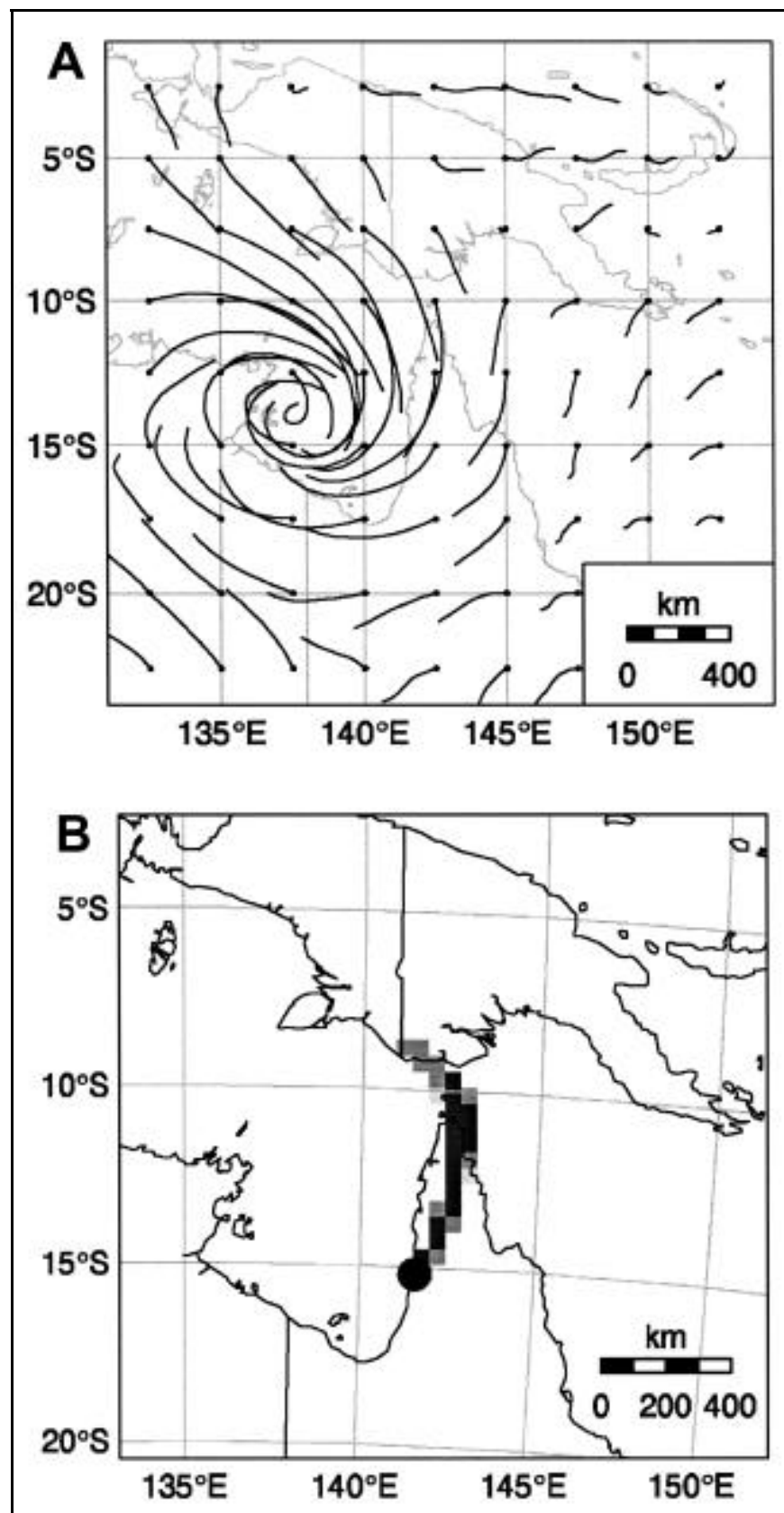

Figure 2. The estimated flight trajectories at $100 \mathrm{~m}$ (A) and backtrack simulations (B) of mosquitoes from the Mitchell River for December 27, 1997. Shading represents the number of back trajectory endpoints per $\mathrm{km}^{2}$ per million simulated mosquito trajectories, with white $=0$, light $=<10$, medium 10 to 20 , and dark $>20$.

is dominated by lowland swamps and lakes. In late 1997 and early 1998, a severe drought created stagnant wetlands, producing high populations of Cx. annulirostris (3). In F ebruary 1998, 39\% of 26 light trap collections in the southeastern part of the Western Province of Papua New Guinea contained $>10,000$ female $C x$. annulirostris (C. J ohansen, unpub. data), and J $E$ virus was isolated from them. Third, substantial numbers of the Cx. annulirostris vector must exploit high winds in the atmospheric boundary layer for long-distance travel. Female Cx. annulirostris have been collected at altitudes $\leq 310 \mathrm{~m}$ in western New South Wales at densities comparable with those of mosquitoes collected in
India and China (8). Finally, wind speed and direction must be capable of carrying the vector to the area in question.

Our results suggest that the necessary wind conditions occur annually in the Torres Strait but only rarely beyond the northern peninsula area of Cape York Peninsula (Table). Monsoonal winds are typically westerly to west-northwesterly in the Torres Strait; mosquitoes carried from New Guinea by these winds would bypass all but the northernmost Torres Strait islands. The rarity of J E virus incursions deep into Cape York Peninsula indicates that it is an extreme, episodic event. Our simulations link the 1995 and $1998 \mathrm{~J} \mathrm{E}$ virus incursions with tropical low-pressure systems west of Cape York Peninsula. These large systems can sustain northerly winds capable of carrying mosquitoes from New Guinea or even Badu I sland into Cape York Peninsula. In addition, the convergent winds and unstable atmosphere of these low-pressure systems would enhance entrainment of mosquitoes into the upper boundary layer. Associated storms with heavy rain would aid mosquitoes' descent to land. Large-scale migration of insects, including mosquitoes, is often associated with large-scale weather systems with extensive wind fields (14), such as tropical low-pressure systems.

Direct evidence confirms that Cx. annulirostris travel from Papua New Guinea into northern Australia. Electrophoretic analysis of $\mathrm{Cx}$. annulirostris populations collected from 1996 to 1998 in Papua New Guinea, the Torres Strait, and Cape York indicates substantial gene flow, indicating dispersal between the populations $(\mathrm{H}$. Chapman and $\mathrm{S}$. Ritchie, unpub. data).

Despite evidence that windborne mosquitoes could have introduced J E virus into northern Australia, additional field studies should be conducted. Northerly winds originating from New Guinea can be sampled for Culexmosquitoes and other potential vectors. Other incursion mechanisms, such as the movement of viremic birds and fruit bats, need to be investigated, as well as their ability to infect Culexmosquitoes.

\section{Acknowledgments}

We thank C. J ohansen, B. Montgomery, and D. Harley for reviewing the manuscript, and G. J ackson of the Bureau of Meteorology, Darwin, for providing weather data.

Dr. Ritchie is medical entomologist with the Tropical Public Health Unit, Queensland Health, in Cairns, Australia. His main interest is in the ecology and intervention of vector-borne diseases, such as J apanese encephalitis and dengue, in north Queensland, Australia.

Dr. Rochester, Department of Zoology and Entomology, University of Queensland, develops simulation models to predict movements of insect pests in Australia.

\section{References}

1. Mackenzie J . Emerging viral diseases: An Australian perspective. Emerg Infect Dis 1998;5:1-8.

2. Hanna J N, Ritchie SA, Phillips DA, Lee J M, Hills SL, van den Hurk AF, et al. An outbreak of J apanese encephalitis in the Torres Strait, Australia, 1995. Med J Aust 1996;165:256-60.

3. Hanna J N, Ritchie SA, Phillips DA, Shield J , Bailey MC, Mackenzie J S, et al. J apanese encephalitis in north Queensland, Australia, 1998. Med J Aust 1999;170:533-6. 


\section{Dispatches}

4. J ohansen CA, van den Hurk AF, Ritchie SA, Zborowski P, Nisbet $D, P a r u R$, et al. I solation of J apanese encephalitis virus from mosquitoes (Diptera: Culicidae) collected in the Western Province of Papua New Guinea, 1997-1998. Am J Trop Med Hyg 2000;62:631-8.

5. Ritchie SA, Phillips D, Broom A, Mackenzie J , Poidinger M, van den Hurk AF. Isolation of J apanese encephalitis virus from Culex annulirostris in Australia. Am J Trop Med Hyg 1997;56:80-4.

6. Ming J -G, J in H, Riley J R, Reynolds DR, Smith AD, Wang RL, et al. Autumn southward 'return' migration of the mosquito Culex tritaeniorhynchus in China. Med Vet Entomol 1993:7:323-7.

7. Reynolds DR, Smith AD, Mukhopadhyay S, Chowdhury AK, De BK, Nath PS, et al. Atmospheric transport of mosquitoes in northeast I ndia. Med Vet Entomol 1996;10:185-6.

8. Kay BH, Farrow RA. Mosquito (Diptera: Culicidae) dispersal implications for the epidemiology of J apanese and Murray valley encephalitis in Australia. J Med Entomol 2000;37:797-801.
9. Melville LF, Pritchard LI, Hunt NT, Daniels PW, Eaton B. Genotypic evidence of incursions of new strains of bluetongue viruses in the Northern Territory. Arbovirus Res Aust 1997;7:181-6.

10. Dyce AL. Distribution of Culicoides (Avaritia) spp. (Diptera: Ceratopogonidae) west of the Pacific Ocean. Arbovirus Res Aust 1982;3:35-43.

11. Rochester WA, Dillon ML, Fitt GP, Zalucki MP. A simulation model of the long-distance migration of Helicoverpa spp. moths. E cological Modelling 1996;86:151-6.

12. J ohnson CG. Migration and dispersal of insects by flight. London: Methuen and Co. Ltd.; 1969.

13. Konno J, Endo K, Agatsuma H, I shida N. Cyclic outbreaks of $\mathrm{J}$ apanese encephalitis among pigs and humans. Am J Epidemiol 1966;84:292-9.

14. Pedgley DE. Windborne pests and diseases. Chichester, UK: Ellis Horwood; 1982. 